\title{
Gender and survival from out-of-hospital cardiac arrest: a New Zealand registry study
}

\author{
Bridget Dicker, ${ }^{1,2}$ Kate Conaglen, ${ }^{2}$ Graham Howie $^{2}$
}

${ }^{1}$ Clinical Development, St John, Auckland, New Zealand

${ }^{2}$ Paramedicine, Auckland University of Technology, Auckland, New Zealand

\section{Correspondence to} Dr Bridget Dicker, Clinical development, St John, Auckland 1060, New Zealand; bridget.dicker@stjohn.org.nz

Received 8 September 2017 Revised 7 March 2018 Accepted 21 March 2018

Check for updates

\section{To cite: Dicker $B$}

Conaglen K, Howie G.

Emerg Med J Epub ahead

of print: [please include Day

Month Year]. doi:10.1136/

emermed-2017-207176

\section{ABSTRACT}

Objective To determine the relationships between survival from all-cause out-of-hospital cardiac arrest (OHCA) and gender in New Zealand.

Methods A retrospective observational study was conducted using data compliant with the Utstein guidelines from the St John New Zealand OHCA Registry for adult patients who were treated for an OHCA between 1 October 2013 and 30 September 2015. Univariate logistic regression was used to investigate factors associated with return of spontaneous circulation sustained to handover at hospital and survival to 30 days. Multivariate logistic regression models were used to investigate outcome differences in survival according to gender at 30 days postevent.

Results Women survived to hospital handover in 29\% of cases, which was not significantly different from men (31\%). When adjusted for age, location, aetiology, initial rhythm and witnessed status, there was no significant difference in 30-day survival between men (16\%) and women (13\%) (adjusted OR 1.22, 95\% Cl (0.96 to 1.55), $\mathrm{p}=0.11)$.

Conclusion No statistical differences were found in 30-day survival between genders when adjustments for unfavourable Utstein variables were accounted for.

\section{INTRODUCTION}

Combined-gender reports, with patient data collected according to Utstein guidelines, have consistently associated survival to hospital discharge with witnessed arrest, bystander cardiopulmonary resuscitation (CPR), emergency services' response times and initial shockable rhythm. ${ }^{1}$ Are these favourable survival elements similar between genders? Are survival rates similar? Internationally, some common patterns have emerged: for example, women who suffer out-of-hospital cardiac arrest (OHCA) are significantly older than their male counterparts; their initial rhythm is less likely to be shockable and more likely to be pulseless electrical activity (PEA) or asystole compared with men; women tend to suffer OHCA at home rather than in public or workplaces; and women tend to receive less bystander CPR. ${ }^{2-20}$ These differences in arrest characteristics have been reported almost universally. However, the data on survival are more mixed. Generally, a preliminary univariate analysis reveals that women have higher rates of survival to hospital admission following OHCA, despite their lower rates of shockable rhythms and bystander CPR, but they have lower rates of survival to hospital discharge (or 30-day survival). ${ }^{371213171920}$ However, these gender differences often change

\section{Key messages}

What is already known on this subject

- Women who suffer out-of-hospital cardiac arrest (OHCA) are significantly older than their male counterparts; their initial rhythm is less likely to be shockable and women tend to suffer OHCA at home rather than in public or workplaces.

- These differences in OHCA characteristics have been reported almost universally.

- However, the survival data for women in OHCA remain controversial.

- Some studies report no difference in survival to discharge or 30-day survival between sexes; or sometimes men appear statistically advantaged, or sometimes women.

What this study adds

- A retrospective observational study was conducted using data from the St John New Zealand OHCA Registry for adult patients who were treated for an OHCA between 1 October 2013 and 30 September 2015.

- This study found no significant difference in survival between men and women at 30 days, once adjustments for unfavourable Utstein variables were accounted for.

on multivariate analysis, where factors such as initial shockable rhythm and paramedic response time appear to be more influential determinants of survival than gender. Thus, some multivariate studies report no difference in survival to discharge or 30-day survival between sexes; or sometimes men appear statistically advantaged, or sometimes women. ${ }^{3}$ 5-8 12 13 15-17 Interestingly, several studies have shown that women of reproductive years may exhibit enhanced survival compared with older women. ${ }^{5613}$ This is the so-called 'oestrogen effect', reported by some but not all studies. ${ }^{17}$ Thus, the survival data for women in OHCA remain controversial. The aim of this study is to use New Zealand registry-based data to provide additional information on the relationship between gender and survival at 30 days.

\section{METHODS}

\section{Study design}

This was a retrospective observational study. Data were included in the analysis if the OHCA occurred between 1 October 2013 and 30 September 2015, if a resuscitation attempt was made by the responding 
Table 1 Characteristics of overall sample and by gender for all attempted resuscitations

\begin{tabular}{|c|c|c|c|c|c|}
\hline Variables & $\begin{array}{l}\text { Missing data } \\
\mathrm{n}(\%)\end{array}$ & $\begin{array}{l}\text { Total, } \mathrm{n}=3862 \\
\mathrm{n}(\%)\end{array}$ & $\begin{array}{l}\text { Male, } n=2678 \\
n(\%)\end{array}$ & $\begin{array}{l}\text { Female, } n=1184 \\
n(\%)\end{array}$ & $P$ values* \\
\hline Age, median (IQR) & $8(0.2)$ & $66(53-77)$ & $65(53-76)$ & $68(54-78)$ & $<0.001$ \\
\hline \multicolumn{6}{|l|}{ Location } \\
\hline Public & & $750(20)$ & $606(23)$ & $144(12)$ & \\
\hline Home & & $2568(67)$ & $1689(63)$ & $879(75)$ & \\
\hline Aged care & & $118(3)$ & $76(3)$ & $42(4)$ & \\
\hline Healthcaret & & $75(2)$ & $51(2)$ & $24(2)$ & \\
\hline Other & $14(0.4)$ & $337(9)$ & $246(9)$ & $91(8)$ & $<0.001$ \\
\hline \multicolumn{6}{|l|}{ Aetiology } \\
\hline Cardiac & & $2982(77)$ & $2119(79)$ & $863(73)$ & \\
\hline Non-cardiac & $0(0)$ & $880(23)$ & $559(21)$ & $321(27)$ & $<0.001$ \\
\hline \multicolumn{6}{|l|}{ Initial rhythm } \\
\hline Shockable & & $1482(38)$ & $1153(43)$ & $329(28)$ & \\
\hline Non-shockable & $1(0)$ & $2379(62)$ & $1524(57)$ & $855(72)$ & $<0.001$ \\
\hline \multicolumn{6}{|l|}{ Witnessed } \\
\hline Unwitnessed & & $1194(31)$ & $801(30)$ & $393(33)$ & \\
\hline Bystander & & $2033(53)$ & $1459(55)$ & $574(49)$ & \\
\hline Crew & $0(0)$ & $635(16)$ & $418(16)$ & $217(18)$ & 0.002 \\
\hline \multicolumn{6}{|l|}{ CPR prior } \\
\hline No & & $1441(38)$ & $958(36)$ & $483(41)$ & \\
\hline Yes & $24(0.6)$ & $2397(63)$ & $1705(64)$ & $692(59)$ & 0.002 \\
\hline Minutes to scene, median (IQR) & $15(0.4)$ & $9(7-12)$ & $9(7-12)$ & $9(6-12)$ & 0.83 \\
\hline \multicolumn{6}{|c|}{$\mathrm{PCl}$ capability of the receiving hospital } \\
\hline None & & $454(35)$ & $326(36)$ & $128(33)$ & \\
\hline 24 hours & & $530(41)$ & $367(40)$ & $163(42)$ & \\
\hline Business hours & $0(0)$ & $324(25)$ & $223(24)$ & $101(26)$ & 0.59 \\
\hline \multicolumn{6}{|l|}{ ROSC on handover } \\
\hline No & & $2696(70)$ & $1858(69)$ & $838(71)$ & \\
\hline Yes & $0(0)$ & $1166(30)$ & $820(31)$ & $346(29)$ & 0.38 \\
\hline \multicolumn{6}{|l|}{ 30-Day survival } \\
\hline No & & $3279(85)$ & $2243(84)$ & $1036(88)$ & \\
\hline Yes & $3(0.1)$ & $580(15)$ & $432(16)$ & $148(13)$ & 0.003 \\
\hline
\end{tabular}

${ }^{*} \mathrm{P}<0.05$ is significant; $\chi^{2}$ test for nominal values and Mann-Whitney for continuous variables.

tHealthcare refers to non-hospital treatment localities such as a general practice clinic.

CPR, cardiopulmonary resuscitation; $\mathrm{PCl}$, percutaneous coronary intervention; ROSC, return of spontaneous circulation.

ambulance crew and if the patient was an adult ( $\geq 16$ years). These data are inclusive of all patients with any cause of cardiac arrest (including traumatic) and all non-conveyances. Patients who were younger than 16 years old or where resuscitation was not attempted by the responding ambulance staff were excluded from the analysis.

\section{Utstein style guidelines}

The template for recording resuscitation outcome variables is referred to as the Utstein style guidelines with an individual variable being an Utstein element. ${ }^{1}$ The registry data used in this study were collected prospectively in accordance with the Utstein style guidelines.

\section{St John New Zealand OHCA Registry}

The St John New Zealand OHCA Registry (SOCAR) was established in 2013. The SOCAR covers 4018370 people (90\% of the New Zealand population) and includes all New Zealand except for the Greater Wellington region, which is serviced by Wellington Free Ambulance. ${ }^{21}$

The data variables held within SOCAR include Computer Aided Dispatch data, on-scene data collected by the ambulance officers in attendance and mortality data from the New Zealand National Health Index. ${ }^{22}$

A cardiac arrest was defined as the patient being unconscious and pulseless with either agonal breathing or no breathing. An attempted resuscitation was defined as the performance of CPR by or under the direction of responding staff, or the delivery of a shock at any time (including before ambulance arrival). Return of spontaneous circulation (ROSC) was defined as survived event, that is, ROSC sustained to hospital handover.

\section{Setting}

St John operates a two-tiered response system for responding to OHCA. Both tiers of the response are dispatched concurrently. The first tier involves the immediate dispatch of the closest resource regardless of qualification, which may be an emergency ambulance or any other coresponder including the St John Patient Transfer Service, New Zealand Fire Service, local first response groups, or Primary Response in Medical Emergencies doctors and nurses. The second-tier response includes an intensive care paramedic (ICP) or a paramedic (PARA) if no ICP is available. All St John personnel follow written St John Clinical Procedures and Guidelines, which provide direction for 
Table 2 Logistic regression, survival to 30 days

\begin{tabular}{|c|c|c|c|c|}
\hline & \multicolumn{2}{|l|}{ Unadjusted } & \multicolumn{2}{|l|}{ Adjusted } \\
\hline & OR $(95 \% \mathrm{Cl})$ & $\begin{array}{l}\text { P values, } \\
\text { significance }<0.05\end{array}$ & OR $(95 \% \mathrm{Cl})$ & $\begin{array}{l}\text { P values, } \\
\text { significance }<0.05\end{array}$ \\
\hline Sex: male (reference) & $0.74(0.61$ to 0.91$)$ & 0.004 & $1.22(0.96$ to 1.55$)$ & 0.11 \\
\hline Age in years & 0.99 (0.98 to 0.99$)$ & $<0.001$ & 0.98 (0.97 to 0.98$)$ & $<0.001$ \\
\hline \multicolumn{5}{|l|}{ Location: public (reference) } \\
\hline Home & $0.28(0.22$ to 0.34$)$ & $<0.001$ & $0.43(0.34$ to 0.55$)$ & $<0.001$ \\
\hline Aged care & 0.05 (0.01 to 0.18$)$ & $<0.001$ & 0.09 (0.02 to 0.39$)$ & $<0.001$ \\
\hline Healthcare & 2.39 (1.48 to 3.87$)$ & $<0.001$ & 2.79 (1.57 to 4.95$)$ & $<0.001$ \\
\hline Other & $0.90(0.67$ to 1.21$)$ & 0.49 & 0.67 (0.46 to 0.98$)$ & 0.04 \\
\hline \multicolumn{5}{|l|}{ Aetiology: cardiac (reference) } \\
\hline Non-cardiac & 0.35 (0.27 to 0.47$)$ & $<0.001$ & $0.47(0.33$ to 0.68$)$ & $<0.001$ \\
\hline Initial rhythm: shockable (reference) & 0.08 (0.07 to 0.11$)$ & $<0.001$ & & \\
\hline \multicolumn{5}{|l|}{ Witnessed: unwitnessed (reference) } \\
\hline Bystander & 4.43 (3.29 to 5.96$)$ & $<0.001$ & $2.22(1.61$ to 3.06$)$ & $<0.001$ \\
\hline Crew & 7.97 (5.76 to 11.02$)$ & $<0.001$ & 8.69 (5.94 to 12.70$)$ & $<0.001$ \\
\hline Bystander CPR: no CPR (reference) & $0.90(0.75$ to 1.08$)$ & 0.24 & & \\
\hline Minutes to scene & $0.98(0.97$ to 1.00$)$ & 0.01 & & \\
\hline \multicolumn{5}{|l|}{ PCI: no PCI (reference) } \\
\hline 24 hours & $1.28(0.99$ to 1.65$)$ & 0.06 & & \\
\hline Business hours & $1.00(0.75$ to 1.33$)$ & 0.99 & & \\
\hline
\end{tabular}

Adjusted for age, location, aetiology, initial rhythm and witnessed status.

$\mathrm{CPR}$, cardiopulmonary resuscitation; $\mathrm{PCl}$, percutaneous coronary intervention.

the personnel to autonomously decide whether it is appropriate to start or terminate a resuscitation.

\section{Statistical methods}

The categorical variables were described as total and percentages of total numbers. The continuous variables were summarised as means \pm SD or medians with IQRs. Survival to 30 days postOHCA event was the primary outcome. The secondary outcome was event survival, which was defined as ROSC sustained to handover at hospital. Univariate logistic regression was used to investigate factors associated with ROSC sustained to handover at hospital and survival to 30 days. Data are presented as ORs with 95\%CIs. Multivariate logistic regression models were used to investigate outcome differences in survival according to gender at 30 days postevent. Logistic regression was also used to conduct subgroup analyses investigating survival between genders in patients who were at a younger age (18-44 years), older age ( $\geq 55$ years) or presented with a shockable rhythm. Selection of covariates for the adjusted models used the forward selection (conditional) method. This is a stepwise selection method with entry testing based on the significance of the score statistic $(<0.1)$, and removal testing based on the probability of a likelihood ratio statistic based on conditional parameter estimate. Data analysis was performed using IBM SPSS (V.23.0). A p value $<0.05$ was considered statistically significant.

\section{RESULTS}

In total 3862 patients were included in the analysis, of whom 1184 (31\%) were female and 2678 (69\%) were male. The median age for women was 68 years and the median age for men was 65 years. The overall rate of survival to 30 days for both sexes was $15 \%$.

\section{OHCA characteristics}

The characteristics of OHCAs in women differed significantly from men (table 1). Women were older, more likely to be at home, have a non-cardiac cause, present in a non-shockable rhythm, were more likely to have unwitnessed arrests and have no CPR performed prior to ambulance arrival compared with men. There was no difference in the time taken by the ambulance to reach the patient, a median of $9 \mathrm{~min}$ for both men and women, nor was there any difference between genders in the percutaneous coronary intervention capability of the receiving hospital $\left(\mathrm{X}^{2}, \mathrm{p}=0.59\right)$.

\section{Event survival: ROSC sustained to hospital handover}

Women survived to hospital handover in $29 \%$ of cases, which was not significantly different from men (31\%) (unadjusted logistic regression OR $0.94,95 \%$ CI $(0.81$ to 1.09$), p=0.38)$.

\section{Survival at 30 days}

The unadjusted results indicated that women had a lower survival to 30 days $(13 \%)$ compared with men $(16 \%)$ (unadjusted OR $0.74,95 \%$ (CI 0.61 to 0.91 ), $\mathrm{p}=0.004$ ) (table 2). When adjusted for age, location, aetiology, initial rhythm and witnessed status, there was no significant difference in likelihood of survival between men and women (adjusted OR $1.22(0.96$ to1.55, $\mathrm{p}=0.11$ ) (table 2).

\section{Survival in age ranges $18-44$ years vs $>55$ years and shockable initial rhythm, by gender}

Analyses were performed to determine any differences between men and women when they were categorised into subgroups of shockable initial rhythm, age $18-44$ and age $\geq 55$. This allowed us to investigate whether there was a survival benefit for women of reproductive years versus postmenopausal women. Characteristics of these subgroups are shown in table 3 .

In the subgroup of shockable initial rhythm, logistic regression analysis indicated that there was a 30-day survival benefit for women (35\%) over men (32\%) (adjusted OR 1.38, 95\% CI (1.03 to 1.84$), \mathrm{p}=0.03$ ) (table 4 ). 


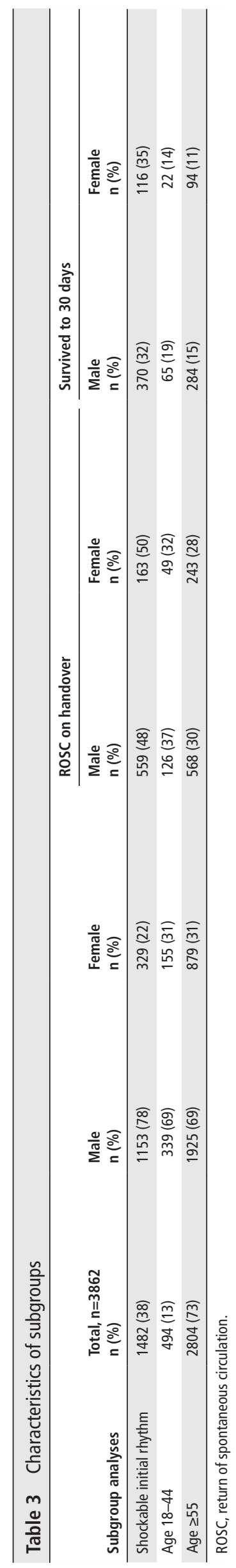

\begin{tabular}{|c|c|c|c|c|}
\hline \multirow[b]{2}{*}{ Subgroup } & \multicolumn{2}{|l|}{ Unadjusted } & \multicolumn{2}{|l|}{ Adjusted } \\
\hline & OR $(95 \% \mathrm{Cl})$ & $\begin{array}{l}\text { P values, } \\
\text { significance } \\
<0.05\end{array}$ & OR $(95 \% \mathrm{Cl})$ & $\begin{array}{l}\text { P values, } \\
\text { significance } \\
<0.05\end{array}$ \\
\hline $\begin{array}{l}\text { Shockable } \\
\text { initial rhythm }\end{array}$ & 1.15 (0.89 to 1.49$)$ & 0.29 & 1.38 (1.03 to 1.84$)$ & 0.03 \\
\hline Age 18-44 & 0.70 (0.41 to 1.18$)$ & 0.18 & 0.92 (0.49 to 1.72$)$ & 0.78 \\
\hline Age $\geq 55$ & 0.69 (0.54 to 0.89$)$ & 0.003 & 1.09 (0.82 to 1.46$)$ & 0.54 \\
\hline
\end{tabular}

Adjusted for age, location, aetiology, initial rhythm and witnessed status.

In the premenopausal age group of 18-44, there was no difference found in 30-day survival between men and women (adjusted OR 0.92, 95\% CI (0.49 to 1.72), $\mathrm{p}=0.78)$ (table 4). Similarly, when men and postmenopausal women aged $\geq 55$ were compared, there was also no difference found in survival to 30 days (adjusted OR $1.09,95 \%$ CI (0.82 to 1.46), $\mathrm{p}=0.54)($ table 4).

\section{DISCUSSION}

Gender differences identified within the New Zealand OHCA Registry are in line with world trends. New Zealand adult women suffer OHCA at less than half the rate that men do and are 3 years older on average. There are significant gender differences in location of arrest, aetiology, initial rhythm, whether the arrest was witnessed and whether or not bystander CPR was initiated.

In terms of ROSC rates and survival to hospital admission, there was no gender difference. Overall this was true even for shockable rhythms. There was no gender difference found in 30-day survival.

This result is reassuring in terms of ambulance performance, both operationally and in the resuscitation skills of New Zealand paramedics. It is unlikely given these results that there was any disparity in care delivery between men and women.

The age distribution of OHCA is remarkably different in men versus women. Men tend to arrest at an earlier age; up until the age of 70 , the percentage of total arrests in men always exceeds that of women; this means that only $38 \%$ of male OHCAs occur in men 70 years or older, whereas $47 \%$ of all female OHCAs occur in this age grouping. ${ }^{23}$ The fact that women arrest at older age ranges and tend to suffer from more comorbidities such as hypertension and diabetes may contribute to their receiving less resuscitation attempts. ${ }^{1424}$

Moreover, less of these female OHCAs occur in public places, a location where they would be more likely to be witnessed and more likely to receive bystander CPR. Resuscitation attempts are less frequent when an arrest occurs at home-there are less people available to resuscitate the victim, generally they are less competent at CPR and partners of older women are more likely to be elderly themselves.

Because of the real differences in OHCA characteristics between genders, and the unfavourable Utstein predictors evident in women, it might be expected that women would experience lower survival rates than men. Our data suggest otherwise. However, this study reports OHCA from all causes, including traumatic arrests; in all, $77 \%$ were of primary cardiac aetiology. This may be a limitation. There is recent evidence to suggest that the usual favourable Utstein factors, other than shockable rhythm, may not be associated with positive outcomes in OHCA secondary to trauma. ${ }^{25}$ 
Some have argued, because women suffer OHCA less than men, that the male form of the disease has dominated and may even have determined general treatment guidelines, perhaps to the detriment of female victims. ${ }^{16}$ Our New Zealand data cannot support this. The similar survival rates between men and women show that gender is not a determinant in itself, in either ROSC rates or 30-day survival post-OHCA.

Some work has reported an overall effect on survival for women of reproductive age, while others have reported no difference in younger versus older women. ${ }^{5-7} 9131517$ Studies have also reported specifically on survival from shockable rhythms. ${ }^{11}$ Bosson et al argued against sex-hormone effects, believing that disparities in outcome could be accounted for by OHCA characteristics and postresuscitation care differences. In our study the subgrouping of shockable initial rhythm indicated a survival benefit for women. In the subgroupings of age 18-44 years and age $\geq 55$, with adjustment for Utstein characteristics, there was no difference in survival between genders or evidence of a so-called 'oestrogen effect' within women. Thus any 'oestrogen effect' remains controversial.

\section{CONCLUSIONS}

No statistical differences were found between genders when adjustments for unfavourable Utstein variables were accounted for.

Acknowledgements We would like to acknowledge the help and support from the St John Clinical Audit and Research Team.

Contributors All of the authors meet the conditions outlined for authorship as per the International Committee of Medical Journal Editors (ICMJE): They have made substantial contributions to the conception or design of the work; or the acquisition, analysis or interpretation of data for the work; drafting the work or revising it critically for important intellectual content; final approval of the version to be published; and agree to be accountable for all aspects of the work in ensuring that questions related to the accuracy or integrity of any part of the work are appropriately investigated and resolved.

Funding This study was supported by an Auckland University of Technology Summer Studentship Grant. The authors have no other financial support to declare.

Competing interests One of the authors is an employee of the St John ambulance service, which may pose a competing interest.

Patient consent Not required.

Ethics approval Ethical approval for research using non-identifiable OHCA data was obtained from the Auckland University of Technology Ethics Committee (13/367) and the New Zealand Health and Disabilities Ethics Committee (13/STH/192/AM02).

Provenance and peer review Not commissioned; externally peer reviewed.

(c) Article author(s) (or their employer(s) unless otherwise stated in the text of the article) 2018. All rights reserved. No commercial use is permitted unless otherwise expressly granted.

\section{REFERENCES}

1 Perkins GD, Jacobs IG, Nadkarni VM, et al. Cardiac arrest and cardiopulmonary resuscitation outcome reports: update of the utstein resuscitation registry templates for out-of-hospital cardiac arrest: a statement for healthcare professionals from a task force of the International Liaison Committee on Resuscitation (American Heart Association, European Resuscitation Council, Australian and New Zealand Council on Resuscitation, Heart and Stroke Foundation of Canada, InterAmerican Heart Foundation, Resuscitation Council of Southern Africa, Resuscitation Council of Asia); and the American Heart Association Emergency Cardiovascular Care Committee and the Council on Cardiopulmonary, Critical Care, Perioperative and Resuscitation. Resuscitation 2015;96:328-40.

2 Johnson MA, Haukoos JS, Larabee TM, et al. Females of childbearing age have a survival benefit after out-of-hospital cardiac arrest. Resuscitation 2013;84:639-44.

3 Karlsson V, Dankiewicz J, Nielsen N, et al. Association of gender to outcome after outof-hospital cardiac arrest--a report from the International Cardiac Arrest Registry. Crit Care 2015;19:182.

$4 \mathrm{Kim} \mathrm{JJ}$, Hyun SY, Hwang SY, et al. Hormonal responses upon return of spontaneous circulation after cardiac arrest: a retrospective cohort study. Crit Care 2011;15:R53.

5 Kitamura T, Iwami T, Nichol G, et al. Reduction in incidence and fatality of out-of-hospital cardiac arrest in females of the reproductive age. Eur Heart $J$ 2010;31:1365-72.

6 Morrison LJ, Schmicker RH, Weisfeldt ML, et al. Effect of gender on outcome of out of hospital cardiac arrest in the Resuscitation Outcomes Consortium. Resuscitation 2016;100:76-81

$7 \mathrm{Ng}$ YY, Wah W, Liu N, et al. Associations between gender and cardiac arrest outcomes in Pan-Asian out-of-hospital cardiac arrest patients. Resuscitation 2016;102:116-21.

8 Piegeler T, Thoeni N, Kaserer A, et al. Sex and Age Aspects in Patients Suffering From Out-Of-Hospital Cardiac Arrest: a retrospective analysis of 760 consecutive patients. Medicine 2016;95:e3561.

9 Safdar B, Stolz U, Stiell IG, et al. Differential survival for men and women from out-ofhospital cardiac arrest varies by age: results from the OPALS study. Acad Emerg Med 2014:21:1503-11.

10 Wigginton JG, Perman SM, Barr GC, et al. Sex- and gender-specific research priorities in cardiovascular resuscitation: proceedings from the 2014 Academic Emergency Medicine Consensus Conference Cardiovascular Resuscitation Research Workgroup. Acad Emerg Med 2014;21:1343-9.

11 Adielsson A, Hollenberg J, Karlsson T, et al. Increase in survival and bystander CPR in out-of-hospital shockable arrhythmia: bystander CPR and female gender are predictors of improved outcome. Experiences from Sweden in an 18-year perspective. Heart 2011:97:1391-6.

12 Ahn KO, Shin SD, Hwang SS. Sex disparity in resuscitation efforts and outcomes in out-of-hospital cardiac arrest. Am J Emerg Med 2012;30:1810-6.

13 Akahane M, Ogawa T, Koike S, et al. The effects of sex on out-of-hospital cardiac arrest outcomes. Am J Med 2011;124:325-33.

14 Arrich J, Sterz F, Fleischhackl R, et al. Gender modifies the influence of age on outcome after successfully resuscitated cardiac arrest: a retrospective cohort study. Medicine 2006:85:288-94.

15 Bosson N, Kaji AH, Fang A, et al. Sex differences in survival from out-of-hospital cardiac arrest in the era of regionalized systems and advanced post-resuscitation care. J Am Heart Assoc 2016:5:e004131.

16 Bougouin W, Mustafic H, Marijon E, et al. Gender and survival after sudden cardiac arrest: a systematic review and meta-analysis. Resuscitation 2015;94:55-60.

17 Bray JE, Stub D, Bernard S, et al. Exploring gender differences and the 'oestrogen effect' in an Australian out-of-hospital cardiac arrest population. Resuscitation 2013;84:957-63.

18 Dumas F, Grimaldi D, Zuber B, et al. Is hypothermia after cardiac arrest effective in both shockable and nonshockable patients?: insights from a large registry. Circulation 2011:123:877-86.

19 Herlitz J, Engdahl J, Svensson L, et al. Is female sex associated with increased survival after out-of-hospital cardiac arrest? Resuscitation 2004;60:197-203.

20 Perers EA, Bang P., Engdahl A.;, et al. Global incidences of out-of-hospital cardiac arrest and survival rates: Systematic review of 67 prospective studies. Coronary Artery Disease 1999:10:509-14.

21 Beck B, Bray J, Smith K, et al. Establishing the Aus-ROC Australian and New Zealand out-of-hospital cardiac arrest Epistry. BMJ Open 2016;6:e011027.

22 New Zealand Ministry of Health. National Health Index Overview. 2007. http://www. health.govt.nz/our-work/health-identity/national-health-index/national-health-indexoverview (accessed 20 Jun 2017)

23 Dicker B, et al. Out-of-Hospital Cardiac Arrest Registry Annual Report 2013/2014: St John New Zealand. 2014. http://www.stjohn.org.nz/News-Info/Our-Performance/ Cardiac-Arrest-Annual-Report/ (accessed Aug 2017).

24 Herzog E, Tamis J, Aziz EF, et al. A novel program focused on women survivors who were enrolled in a cardiac arrest pathway. Crit Pathw Cardiol 2013;12:28-30.

25 Beck B, Bray JE, Cameron P, et al. Predicting outcomes in traumatic out-of-hospital cardiac arrest: the relevance of Utstein factors. Emerg Med J 2017;34:786-92. 


\section{Gender and survival from out-of-hospital cardiac arrest: a New Zealand registry study}

Bridget Dicker, Kate Conaglen and Graham Howie

Emerg Med J published online April 16, 2018

Updated information and services can be found at:

http://emj.bmj.com/content/early/2018/04/16/emermed-2017-207176

\section{These include:}

References This article cites 23 articles, 5 of which you can access for free at: http://emj.bmj.com/content/early/2018/04/16/emermed-2017-207176\#r ef-list-1

Email alerting service

Receive free email alerts when new articles cite this article. Sign up in the box at the top right corner of the online article.

\section{Notes}

To request permissions go to:

http://group.bmj.com/group/rights-licensing/permissions

To order reprints go to:

http://journals.bmj.com/cgi/reprintform

To subscribe to BMJ go to:

http://group.bmj.com/subscribe/ 